\section{Seventh European Congress of Haematology}

The Seventh European Congress of Haematology was held in London under the presidency of Dr. John F. Wilkinson, Manchester. Brief summaries of some of the papers follow.

\section{Erythropoiesis}

The development of pernicious anaemia was traced by L. J. Wirts (Oxford) mostly to anomalies in the stomach; he pointed out that achlorhydria plays an important part in the production of pernicious anaemia, and stressed the aetiological factors of inheritance. The pathology of the stomach in pernicious anaemia was outlined by $\mathbf{H}$. A. Magnus (London). E. LeSTer SMITH (Greenford, Middx.) described some of the anti-vitamin $B_{12}$ substances. $\mathrm{He}$ pointed out that vitamin $B_{12}$ has not yet been synthesized, but modification of the nucleotide part of the molecule produces analogues which have some vitamin $B_{12}$ activity. The replacement of ammonia in one of the side-chains by methylamine and similar amines, or other bases, produces analogues with an antimetabolite activity. The anti-vitamin $B_{12}$ activity of the substances can be estimated by tests involving bacterial mutants and the growth rate of chicks. M. SCHWARTZ and P. Lous (Copenhagen, Denmark) pointed out that in the treatment of pernicious anaemia, oral preparations of vitamin $B_{12}$ and pyloric mucosa often failed after a good early response due to resistance to the heterologous intrinsic factor. An inhibiting substance is sometimes present in the serum of patients with pernicious anaemia, but on other occasions there may be intestinal blockage.

Folic acid deficiency was investigated by $\mathbf{R}$. $\mathbf{H}$. GiRDwood (Edinburgh), who used folic acid absorption tests and investigated the rise of serum folic acid after a test dose and the urinary contents of glutamic acid. He pointed out that folic acid deficiency may occur in nutritional megaloblastic anaemia, steatorrhoea, after partial gastrectomy, in the presence of blind loops of the intestine, in pregnancy, and in chronic liver disease. The diagnosis of folic-acid deficiency was outlined by I. CHANARIN (London), who described the sequence of the disposal of parenteral doses of folic acid by measuring the excretion of folic acid in the urine and the rate of clearance from the plasma to the tissues.

Sideroblastic anaemia was discussed by $\mathbf{L}$. HeILMEYER (Freiburg, Germany). He grouped together idiopathic, sideroblastic anaemia, thalassaemia, as well as an inherited hypochromic anaemia which does not respond to iron, cobalt, and pyridoxine, and the sideroblastic refractory anaemia which is sometimes accompanied by leucopenia. He assumed that these anaemias were due to an enzyme deficiency. M. Bessis (Paris, France) described his electronic microscope studies in sideroblastic anaemia.
Granules of sideroblasts show different aspects: ferritine molecules may be surrounded by a membrane; mitochondria may be filled with ferritine or they may be filled by other iron fragments more or less mixed with ferritine. At present no distinction can be made between the various sideroblastic anaemias.

C. A. Finch (Seattle) discussed the plasma iron turnover, particularly between the tissues ejecting iron and the plasma. The size of the iron turnover largely depends on the capacity of the erythropoietic marrow to take up iron and therefore is a measure of the activity of the erythroid marrow. L. HALLBERG (Göteborg, Sweden) used a double radio-isotope technique in order to study iron absorption. It was possible to estimate the outflow of iron from the plasma and to calculate also the rate of absorption The relation between the rate of iron absorption and the erythropoietic marrow activity is effected by the plasma iron-transferrin system. There is no evidence of mucosal blockage of iron absorption. After partial gastrectomy, iron-deficiency anaemia is very common. J. R. HoBBs and G. Discombe (London) found that the anaemia was determined by bleeding from some other side, or failure to treat iron depletion, or failure of iron absorption.

C. A. A. SChrumpF (Porsgrunn, Norway) related his experiences with vitamin $B_{12}$ assay in pernicious anaemia. He stressed the importance of prepernicious states after gastrectomy and in sideropenia. A. Doscherholmen, P. Finlay, and P. S. Hagen (Minneapolis, Minn., U.S.A.) estimated the organ distribution of radioactivity in man after the ingestion of radio-labelled vitamin $B_{12}$. They found that vitamin $B_{12}$ moves in and out of several different body compartments: (1) a temporary storage compartment, i.e., the wall of the small intestine ; (2) a transport compartment, i.e., the blood; (3) a permanent storage compartment, i.e., the liver.

J. Q. Matrias (London) studied the survival of red cells in several types of proliferative diseases of unknown aetiology by means of radioactive chromium. Survival was related to fever, size of liver and spleen, degree of anaemia, marrow involvement, and several other tests. L. K. Dinmond and T. SHAHIDI (Boston, Mass., U.S.A.) found that in some cases of aplastic anaemia after much ill success with many other methods of treatment testosterone produced a remission in eight patients when it was combined with corticosteroids.

\section{Myelopoiesis}

In a session on aetiological and experimental aspects of leukaemia presided over by A. Haddow (London), J. ENGelbreTH-Holm (Copenhagen, Denmark) emphasized the changing pathological aspects of leukaemia, pointing out that longer survival gives rise 
to changed morbid anatomical patterns. The role of the thymus in murine lymphomas was discussed by J. F. A. P. Miller (London). He inoculated cell-free filtrate extracts of leukaemic tissues intraperitoneally into newborn and adult mice. Total thymectomy completely prevents the development of leukaemia in mice susceptible to leukaemogenic activity of the filtrates, but thymus grafting restores its potentiality. J. M. Yoffey (Bristol) studied the lymphocytes in the bone marrow of the guinea-pig and found no lymphopoietic foci in normal marrow and very few lymphocytes in mitosis. He suggested that the micromyeloblasts and the primitive cells of Cunningham, Doan, and Sabin are probably small lymphocytes. He found that after sublethal irradiation the number of lymphocytes in the marrow increases about twoand-a-half-fold and then decreases when the red and white cell marrow portions become more active.

The differential diagnosis of monocytic leukaemia was outlined by H. STOBBE (Berlin, Germany), who recognized Schilling and Naegeli types. He suggested that phase-contrast microscopy of living preparations may sometimes contribute to a solution of such diagnostic programmes.

In a session devoted to morphology of leucocytes, E. UNDRITZ (Basel, Switzerland) outlined the hereditary constitutional anomalies of leucocytes and the abnormalities in shape and structure of nucleus or cytoplasm. Leucocyte anomalies are independent of race and sex. Amongst the dominant hereditary anomalies, the best known of the nuclear anomalies is the Pelger-Huët anomaly, and, amongst the cytoplasmic anomalies, the May-Hegglin anomaly. Amongst the recessive hereditary anomalies, he listed Alder's anomaly. The culture of bone marrow in acute leukaemia was illustrated by a film shown by R. J. V. Pulvertaft and J. G. Humble (London).

H. Rieder (Vienna, Austria) found that patients treated for many years with "myleran" sometimes developed unpleasant side-effects such as pigmentation of the skin which, at biopsy, resembles the findings in Addison's disease, and secondary myelosclerosis, which may occasionally completely mask the appearance of myeloid leukaemia. Mannomustin and related sugar compounds had good clinical effects on certain lymphomas, but C. SElleI (Budapest, Hungary) was disappointed in its effect on leukaemias.

Using a skin window technique, P. RIIs (Glostrup, Denmark) investigated the relationship between free inflammatory cells in leukaemia and leucocytes in the blood. He never found leukaemic cells in artificial blisters.

In a session on myeloproliferative syndromes, I. A. KASSIRSKY (Moscow, U.S.S.R.) discussed the clinical picture of osteomyelo-reticulosis, which he regards as an atypical leukaemic process. He found treatment with corticosteroids and "myleran" occasionally belpful.

In a session devoted to abnormalities of globulins, R. DI Guglielmo (Florence, Italy) found an increase of serum mucopolysaccharides in Waldenström's disease. J. R. SQUIRE (Birmingham) reported on the 61 patients observed by the Medical Research Council Working Party on Hypogammaglobulinaemia. In this condition upper respiratory and pulmonary infections predominate. The incidence amongst male children is about 1 per 100,000 births. The disease is regarded as a low production syndrome. This was established by investigations with radioactive-iodinelabelled proteins.

\section{Coagulation and its Disorders}

In a symposium on the clinical use of antihaemophilic globulin, M. BLOMвÄCK and B. BLOMвӥCK (Stockholm, Sweden) outlined the preparation of antihaemophilic globulin (A.H.G.). I. M. NILsson (Malmö, Sweden) discussed the use of human A.H.G. in haemophilia $\mathbf{A}$ and in von Willebrand's disease. Fraction I-O was given to 24 haemophilic patients with very good clinical improvement. No resistance was observed. The plasma A.H.G. levels were increased from 40 to $80 \%$ of the normal before operations and maintained afterwards at 20 to $30 \%$. In cases of von Willebrand's disease purified A.H.G. helped to produce considerable improvement. A.H.G. is not identical with fraction $\mathrm{I}-\mathrm{O}$. P. WolF (Lewisham) described his experience in treating 25 haemophilic patients for troubles with joints, and their prevention; $60 \%$ of large tissue and joint haemorrhages responded to rest alone; only in $9 \%$ of cases treated with human A.H.G. were there some reactions. F. Nour-EldiN (Manchester) discussed the importance of the Bridge anticoagulant in patients to whom A.H.G. had been given. R. BIGGS (Oxford) reported experiences with animal A.H.G. It was found that A.H.G. levels of $5 \%$ may be sufficient to arrest bleeding in a severely affected patient. Sometimes levels of $25 \%$ are necessary.

In a symposium on long-term anticoagulant therapy, P. A. OWren (Oslo, Nerway) described the laboratory and social organization of long-term anticoagulant therapy in Norway. Standardized reagents are prepared at the coagulation laboratory and distributed to all hospitals. The thrombotest is used extensively. It has been found simple and useful and this has led to a great increase in anticoagulant therapy. I. S. Wright, E. MCDeVITT, and J. S. Lieberman (New York, U.S.A.), M. Toohey (London), and A. S. Douglas (Glasgow) discussed various aspects of the problem of long-term anticoagulant therapy.

A. Aas (Oslo, Norway) described the technique of labelling platelets with radioactive chromium. He found that human platelets lived for 9 to 11 days. In idiopathic thrombocytopenic purpura normal platelets survive for only a few hours, but in aplastic anaemia they have a normal survival time. J. $\mathbf{H}$. LEWIS and I. SzeTo (Pittsburgh, Penn., U.S.A.) made observations on normal human platelets and found that the circulating platelet radioactivity levels reach a maximum of 2 to 24 hours. 
The biological equivalents of blood coagulation factors were described by P. DE Nicola (Pavia, Italy). His discussion concerned phospholipid enzymes, Russell viper venom, and physiological fluids such as bile, saliva, and seminal fluid. The genetic aspects of factor VII deficiency were discussed by F. E. Dische (London), who had observed a family, including a woman, with mild haemorrhagic diathesis. G. I. C. INGRAM (London) reported his work on the Bridge anticoagulant.

The interrelationships of vitamin $K_{1}$ and of anticoagulants in the synthesis of prothrombin were discussed by S. A. Johnson and E. McCall Priest (Detroit, Michigan, U.S.A.), and H. B. ANSTALl (London) provided evidence that there may be a substance activating Christmas factor which may be distinct from either the Hageman factor or plasma thromboplastin antecedent (P.T.A.). The role of magnesium on the clotting of human blood was discussed by H. B. Anstall, R. G. Huntsman, B. HuRN, and H. LehmanN (London).

L. B. JaQues and G. A. McMurray (Saskatoon, Canada) described capillary resistance and blood pressure changes associated with pain due to local cooling (the cold pressor test).

\section{Bone Marrow Transplantation}

In a session on bone marrow transplantation, J. F. LouTIT (Harwell, Berks) outlined the process of haemopoiesis after bone marrow transplantation. D. W. Van BekKum (Rijswijk, Holland) discussed the factors influencing the take and the rejection of bone marrow grafts. These factors are antigenic differences between host and donor, the dose of whole body irradiation administered to the host, the time interval between irradiation and transplantation, and the transplantation technique, including the number of donor cells. Marrow transfusion in man was described by G. Mathé and J. Bernard (Paris, France), who stressed the importance of the secondary phenomenon, which usually occurs between 45 and 90 days after irradiation. H. E. M. KAY and M. Constantoulakis (London) sketched the problems of storage and the use of foetal cells. The effect of 6-mercaptopurine on transplantation immunity was discussed by R. Schwartz (Boston, Mass., U.S.A.), who found that these effects are somewhat similar to those found in irradiated cases. Much discussion followed these papers, but it was felt that bone marrow transplantation is by no means fully ready for clinical experiments.

\section{Haemolysis and Haemoglobinopathies}

In a session on genetically determined enzyme defects of erythrocytes, presided over by J. V. Dacie (London), G. SANSONE (Genoa, Italy) discussed favism and allied haemolytic anaemias. Favism causes diminution and marked instability of the blood glutathione, a tendency to form Heinz bodies, and a deficiency of glucose-6 P-dehydrogenase. T. A. J. Prankerd (London) discussed enzyme defects in hereditary spherocytosis.

V. M. Ingram and H. Lehmann (Cambridge, Mass., U.S.A., and London) described chemical studies on haemoglobin $A$ and $S$ and the difference in their amino-acid composition which often involved a charged carboxyl group; this may explain the difference in electrophoretic behaviour. S. CALLENDER (Oxford) described her genetic and clinical studies on thalassaemia in Britain.

A second haemoglobin abnormality in haemoglobin $\mathbf{H}$ disease, involving a "fast" haemoglobin fraction on starch-gel electrophoresis, was described by P. Fessas (Athens, Greece). L. Zannos-Mariolea and P. Chiotakis (Athens, Greece) had investigated 18 families with favism and found that the defect was sex linked. J. V. GARRETT and F. MORTON (Birmingham) described an English family with the thalassaemia trait.

\section{Blood Transfusion}

In a symposium on the detection and significance of weakly reacting antibodies arranged in conjunction with the International Society of Blood Transfusion. presided over by P. L. Mollison (London), several papers concerned the study of chromium-labelled red cells, the Coombs test, antihuman globulin sera and non-gamma-globulin reagents.

In a session on blood group substances, S. D LAWLER (London) described blood group substances in human milk, blood, and saliva. A. E. Szulman (Boston, Mass., U.S.A.) located human blood group antigens $A$ and $B$ by fluorescein-labelled human hyperimmune antisera applied to frozen sections of surgical and necropsy material.

In all the sessions lively discussion followed the papers. It was felt that these discussions and their continuation, even during the social events connected with the Congress, helped to bring together haematologists from all corners of the world and enabled them to understand each other's problems, as well as bringing them together as friends and making bibliography come to life.

\section{VIIIth Colloquium on Protides of Biological Fluids}

The VIIIth colloquium on "Protides of Biological Fluids" will be held from May 6-8, 1960, at St. Jans Hospital, Bruges. For all information please apply to Dr. H. Peeters, The Laboratory, St. Jans Hospital, Bruges, Belgium. 